\title{
Post 1950 advances in floor systems in France
}

\author{
I. P. Cruz \& G. G. Nieuwmeijer \\ Delft University of Technology, Faculty of Architecture, \\ Delft, The Netherlands
}

\begin{abstract}
During the Reconstruction Period (1945-1965) there were a number of developments in the construction industry. In France, the population of the cities increased and the old housing stock was modernized; various improvements were carried out in the construction methods and design during this period which was characterised by many structural innovations and the construction of multifamily buildings. New types of floor systems using structural components such as terracotta, concrete and pre-stressed concrete were introduced. These new materials and methods, using a partial formwork or without formwork, made possible the more rapid construction of higher buildings. This paper considers the typology of these structural systems and includes a selection of illustrations of buildings that were erected during the period in question.

Keywords: floors, reconstruction construction methods, structures, materials, France.
\end{abstract}

\section{Introduction}

In 1945 in France much of the housing stock that had escaped destruction was old, of poor quality and lacking modern amenities like bathrooms, kitchens and running water. During the post war period, the population of France grew from 40.3 million to 53 million and overcrowding was a major problem, compounded by the movement of people from rural to urban areas. To address these needs there was large investment in the housing infrastructure in the 1950s and 1960s. From 1954 onwards, new building projects were completed - les grandes ensembles - often supplanting as well as complementing existing housing stock. At its peak, some 400,000 properties - modern, sanitised, standardised and suburban - were created each year. For this reason this period is sometimes characterized as les années de béton. 
At this time the most typical structural systems incorporated reinforced concrete, reinforced masonry, or steel frames. Structural innovations were introduced, especially in the structure of floors. This paper considers the various methods used to construct floors in France in buildings with a great variety of structural forms and architectural characteristics. The study is based on information collected from French specialist magazines and technical literature in the fields of architecture and civil engineering published after WWII.

\section{General information - materials}

\subsection{The reinforced concrete floors}

In the post war period many prefabricated floors were made from various types of ribbed reinforced concrete slabs, including $\mathrm{T}$ and $\mathrm{U}$ profiles and hollow slabs, generally prefabricated or constructed on site and using sacrificial formwork. Another type of prefabricated floor, which also had supporting ribs, had a hollow body. These types differ from reinforced concrete slabs, since they incorporate manufactured elements intended to reduce, or even to remove the need for formwork and to expose a horizontal underside ready to receive the ceiling plaster. These hollow-body floors formed an important class owing to their wide use in construction programs during the 50's, in particular for dwellings.

Reinforced concrete floors can be classified either according to their construction principle: massive floors, floors incorporating ribs, floors completely prefabricated and articulated like metal floors; or according to the mode of execution: total formwork; partial or no formwork; partial or total prefabrication; or even according to their form: floors with visible ribs, floors on hollow blocks, and massive floors. The latter classification, though less systematic, appears more convenient for the architect (Vitale [5]).

\subsection{Pre-stressed concrete floors}

The development of the pre-stressing process led several brickyards to manufacture beams and also mixed panels from pre stressed concrete and ceramics, a process that permitted a notable reduction of the dead load and thickness. The experience thus acquired showed the technical and economic advantages of pre-stressing in prefabrication. Not only were the pre-stressed mixed elements technically better than the traditional ones (in particular because they resisted cracking), but they also opened new prospects to the terracotta industry. Production was organized rationally and the specialized skills of the production teams led to the achievement of a high degree of efficiency.

\section{Floor types}

\subsection{Floor with exposed ribs}

The simple slab with parallel ribs was the most common type of reinforced concrete floor with exposed ribs. Although it retained the architectural style of 
wooden floors, it permitted practical standardization and simplification of the formwork and allowed a simple expression of the structure, on the aesthetic level.

Floors with exposed ribs were used in medium or large utilitarian buildings, and in office buildings, hospitals and laboratories, with suspended ceilings, permitting the installation of the piping, electrical conduits and lighting.

Floors with box structures, such as honeycombs, were often used when large overloads were expected or, more simply, when it was necessary to create an under surface without springing and a light dead load. They had orthogonal crossed ribs (or sometimes at $60^{\circ}$ ), which produced extremely rigid slabs in two directions and which were relatively thin.

\subsubsection{Floor with exposed ribs with a formwork of pre-stressed concrete}

The Exhibition Centre of the Roundabout of La Defense has large floor with exposed ribs for which pre-stressing was used. It had minimum support points, minimum thickness, high surcharges and relatively low weight.
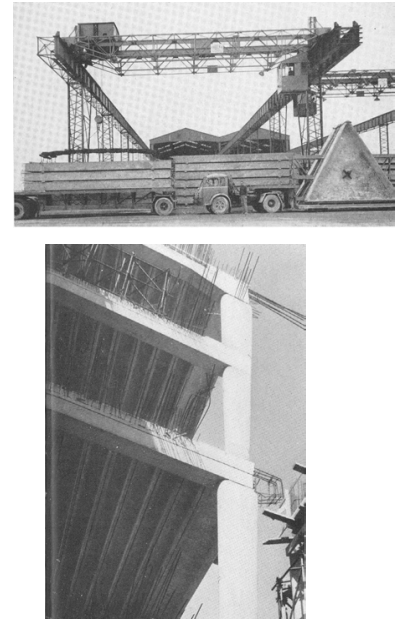

(a)

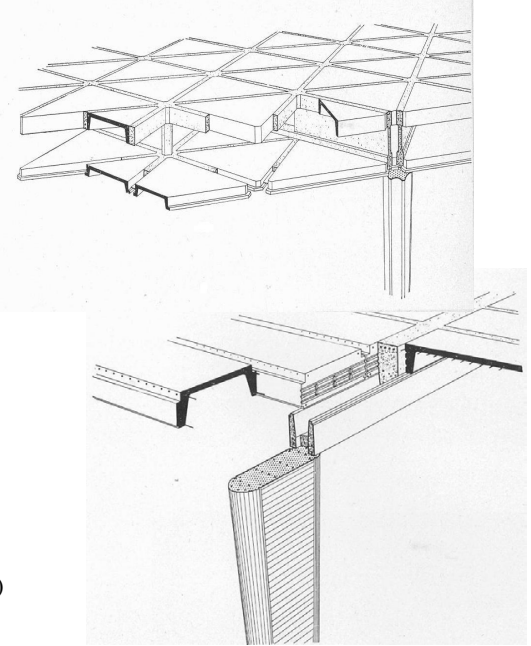

Figure 1: (a) Prefabricated slabs with the shape of pre-stressed triangular boxes in the Palais $d u$ CNIT and diagrammatic view. (b) design of prefabricated floor with the shape of rectangular boxes plus diagrammatic view

The floors of the four storey annexe buildings consist of rectangular prefabricated boxes with concrete filling the grooves of the joints and coating the exposed steel bars, see fig. 1 . For the required ceiling height $(1.8 \mathrm{~m})$ there was a double floor with space for the installations that supplied the stands of exhibitors. The upper floor consisted of $8 \mathrm{~cm}$ thick pre-stressed concrete triangular slabs, supported by beams; the slabs of the lower floor were $6 \mathrm{~cm}$ thick. This floor was installed on a triangular network of posts with a span of $18 \mathrm{~m}$, while the prefabricated slabs had a span of $6 \mathrm{~m}$. The entire unit was supported by pre- 
stressed concrete beams cast on site between the slabs, on the star surrounding each post. The nodes of the $6 \mathrm{~m}$ spans are tied by reinforced concrete props. The upper section of this floor could support a live load of $1000 \mathrm{~kg} / \mathrm{m}^{2}$, while the lower slab could support a live load of $100 \mathrm{~kg} / \mathrm{m}^{2}$.

\subsubsection{Rib slabs made of reinforced concrete.}

Ribbed prefabricated reinforced concrete slabs were made with parallel $T$ profiles or U profiles; (if necessary the side ribs could be used as sides for the formwork for reinforced concrete beams cast on site) see fig. 2, and as hollow slabs, (generally distribution and ceiling slabs and sacrificial formwork), prefabricated in a factory or on site.

During prefabrication on site, the slabs could be cast on top of each other. The smoothed upper face of each slab was covered and formed the bottom of the mould for the following slab. Thus, the lower surface of this slab was a plain concrete surface ready to be painted. Factory prefabricated slabs could be delivered with their floor covering (ceramic or wood) already in place.

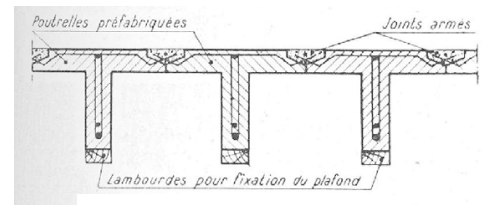

Profiles in T

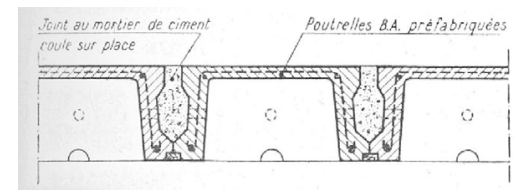

Profiles in U

Figure 2: $\quad$ Profile-types of ribs prefabricated with reinforced concrete.

\subsection{Floors on hollow body.}

These floors incorporated manufactured elements intended to reduce or even avoid the use of formwork. Their horizontal under surfaces were ready to receive the ceiling plaster. They were generally used in residential buildings and are still available in the construction market.
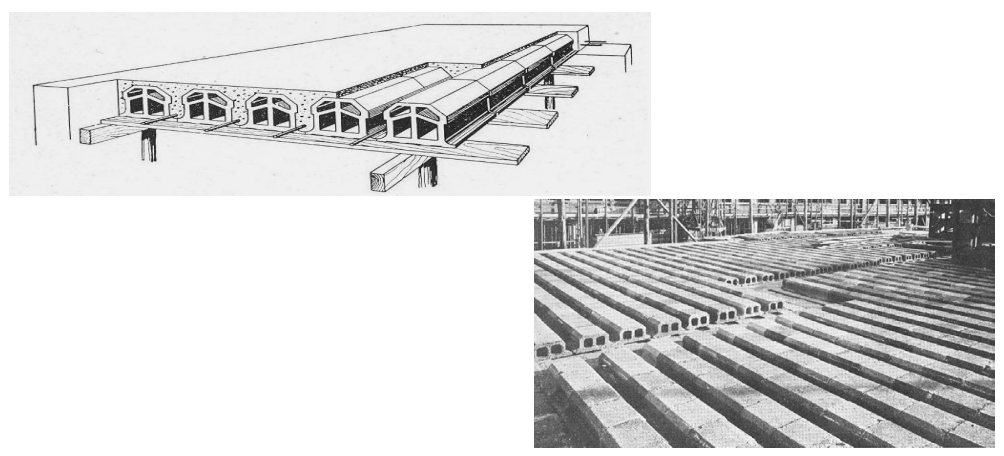

Figure 3: Traditional hollow blocks of terracotta and their layout. 


\subsubsection{Hollow block for floor over partial formwork}

The first sample tests of these floors incorporated terracotta, steel and concrete see fig. 3. These new designs improved sound and thermal insulation. Moreover, there was a reduction of the amount of concrete used. Fibre and hollow concrete elements and other products were then introduced in addition to ceramics and concrete to improve the insulating qualities of the hollow body. Some manufacturers even proposed using straw or reeds see figs. 4 and 5.

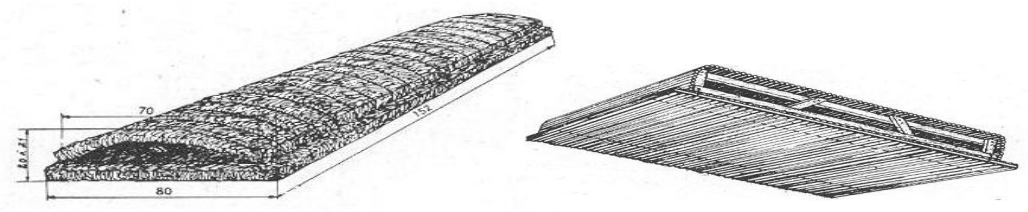

Figure 4: Hollow blocks in compressed straw "Dureau" (left) and "Chauvet" (right).

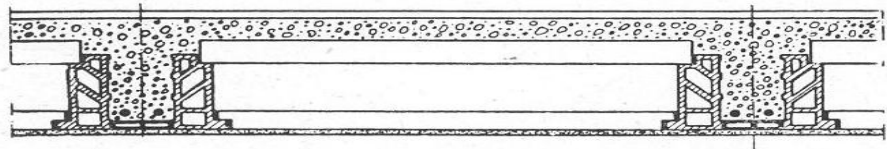

Figure 5: Ceramic floors made up of brick mattress and cement with gravel.

A special formwork system was developed for the construction of the floors. The hollow cement mortar bodies were installed in lines on metal beams with a lattice of $70 \mathrm{~cm}$ (between axes of the hollow blocks), see fig. 6 . These beams comprised a $U$ profile bar at the top and one or two reinforcing bars at the bottom. The diagonals were simple steel bars, welded in place on the frames, see fig. 7. The beams had mobile butts either at one side on the formwork or on the edge beam, and on the other side on the prefabricated central beam. The mobile butts made it possible to adjust the size of the beams according to the various spans. The formwork could be easily dismantled by simply releasing the butts. With this design no stays were required, see fig. 8.

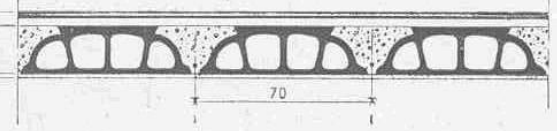

Figure 6: Detail of the floor in hollow body of cement mortar, splayed ribs without clamps. Note the shape of the hollow bodies, Cazaneuve et al. [2].

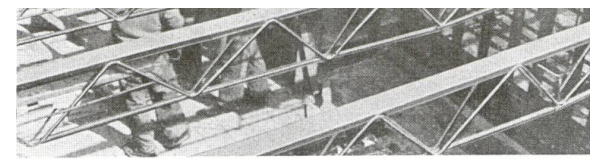

Figure 7: $\quad$ Detail of beams built using a U profile. 


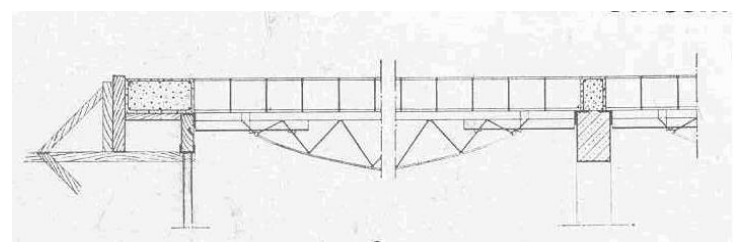

Figure 8: $\quad$ System of formwork for the floor.

\subsubsection{Floors with hollow blocks without formwork}

The design and manufacturing process for the floor with concrete ribs between prefabricated hollow blocks permits the pre-shaping of the beams, thus saving labour during construction and reducing the use of formwork. Since one of the beams is prefabricated, the need for a support during construction is reduced. Moreover interruptions to the construction process for each floor are minimized. These types of floor were highly desired by the users and production rates soared. These floors are classified as follows:

3.2.2.1 Joined beam type. In this design the pre-cast girders were located side by side during installation. Usually there was a central cavity, in which the beam was cast, and steel tension wires were placed at the base of the cavity; other variations were possible.

Floors using prefabricated hollow ceramic blocks and reinforced concrete beams were constructed in the Quartering for the Republican Guard at Courrège in Toulouse [7]. The design was based on the inclusion of large masonry panels in the reinforced concrete skeleton. The $125 \mathrm{~m}$ long and $8.5 \mathrm{~m}$ wide building included eight floors and a basement. The architecture of the new buildings preserved the traditional cityscape by maintaining the brickwork and Latin tiles, which are characteristic of the city of Toulouse.

Reinforced resistant ceramics from Tuileries $d u$ Languedoc were used for all the floors. These hollow ceramic blocks have a final resistance identical to that of the best concretes. The prefabricated beams and intermediate case-bays were supported on the tenons of the main beams see fig. 9 .

After the installation of all the hollow ceramic blocks, the concrete for the longitudinal junctions between ceramic elements was cast on site at the same time as the upper beams of the prefabricated girders, see fig. 10 .

The concrete cast on top of the prefabricated girders flowed to $45^{\circ}$ in the extremities of the hollow ceramic elements, thus ensuring a perfect connection and perfect rigidity of the floors. As a result of the absence of the compression slabs and the small amount of concrete used, these floors had good acoustic properties and their isothermal coefficient was also very efficient. This was a perfect combination of concrete forming the framework and ceramics providing isothermal and sound resistant material for the floors and the prefabricated walls.

The mechanization and the job management at Courrège, associated with the construction process described permitted to the execution of the entire work by a team of less than thirty men. 

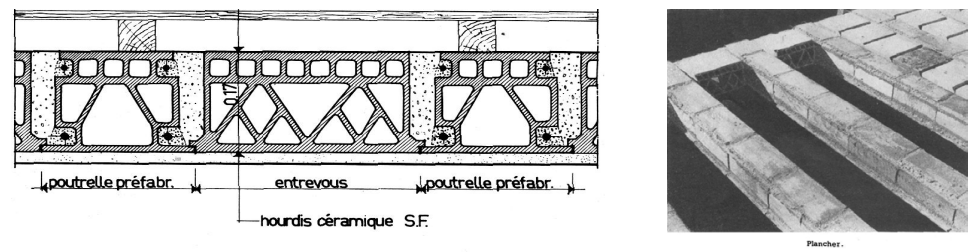

Figure 9: Cross section of the floor.

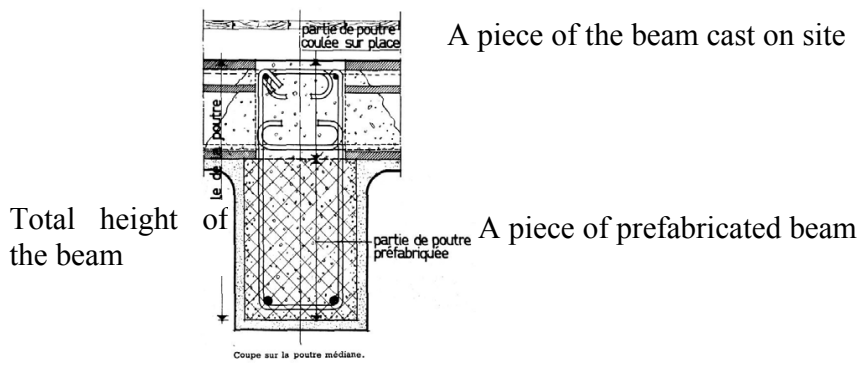

Figure 10: Section of the median beams.

3.2.2.2 Floors using beams and hollow blocks. In these groups of floors, there was either a central rib or a small triangulation of ribs. A hollow body filled out the remaining volume.

There were many variations of this type of floor structure. Where ceramics were included there was an appreciable reduction in weight. Systems also included combinations of vibrated concrete steel wire trellises and folded steel sheets with a concrete sole on which the hollow body rested. Some designs used hollow blocks with a smooth top surface. For tall buildings with a metal skeleton a pile of prefabricated floors could be manufactured, each being used as the formwork for the floor above. These were installed by hoisting within the, see fig. 11 .
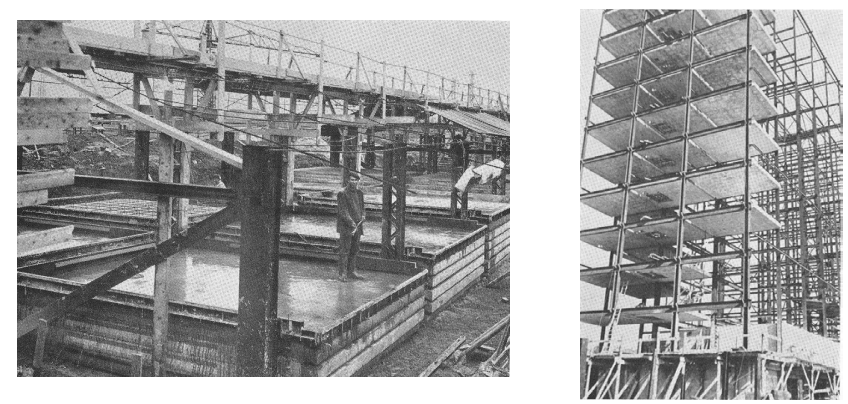

Figure 11: Slabs of floors in hollow body prefabricated by vertical stacking on site: Porte de Lilas and Chevilly-la-Rue (Vitale [5]). 
With the Porte de Lilas project the architect (Fayeton [4]), wished to demonstrate that under certain conditions, the steel framework was able to compete economically with the reinforced concrete for construction of residential buildings. A new association of steel and reinforced concrete was implemented to produce finished surfaces, remove all need for scaffolding or formwork and eliminate any concreting at high elevation.

\subsection{Massive floors}

Floors made of massive reinforced concrete slabs, of constant thickness, were employed in extreme cases: short spans with light load or for very small spans (over beams and small joists). When very high overloads were expected over medium or large spans, "mushroom" supports were used to provide adequate, see fig. 12 .
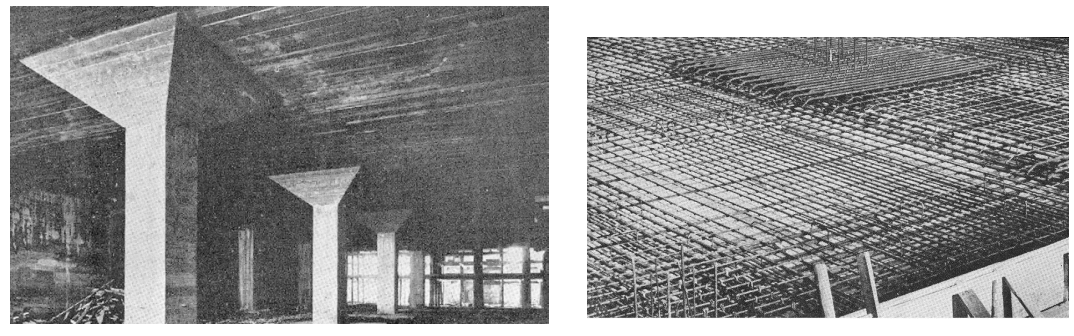

Figure 12: Floor mushroom.

Massive (av.13 cm thick) floor slabs were widely used in the construction of groups of H.L.M. (Habitations à Loyer Modérée). These fitted the commonly used spans ( 3 to $4 \mathrm{~m}$ ) and could be prefabricated in factory or on-site or by using simplified mobile formwork. Due to their inertia they were better insulated than the hollow floors. In addition, heating tubes could be also installed inside the massive slabs, thus providing both floor and ceiling heating with less expense for the residents.

\subsubsection{Prefabrication of massive slab floors}

3.3.1.1 Formwork systems Extensive economic and operational research on formwork systems on building sites was carried out before the implementation of these systems. Oiled steel caissons or laminated coffers impregnated with synthetic resins were usually used, although sometimes wood trellis formworks were also used.

\subsection{Floor types with structural components in terracotta and pre stressed concrete}

Pre-stressed ceramics were developed rapidly during the 1950s. Ceramic floors were always preferred by the manufacturers owing to their lightness and their perfect physical stability. The adaptation of these floors to the pre-stressing techniques using concrete led to the use of two construction systems 
One factory operated used the Swiss Stahlton process and five worked under the license of STUP (Société des Produits Céramiques du Languedoc). These two processes although both making use of pre-stressing by adherent wire, produced different design of the beams.

The Stahlton system incorporated hollow ceramic bodies from Tuileries Réunies du Bas-Rhin, which provided the ceramic hollow bodies, see fig. 13. The Stahlton floor was a relatively heavy floor with remarkable qualities of thermal and noise insulation. Several pre-stressed floors we remanufactured under the license of STUP and the PRECERBA.

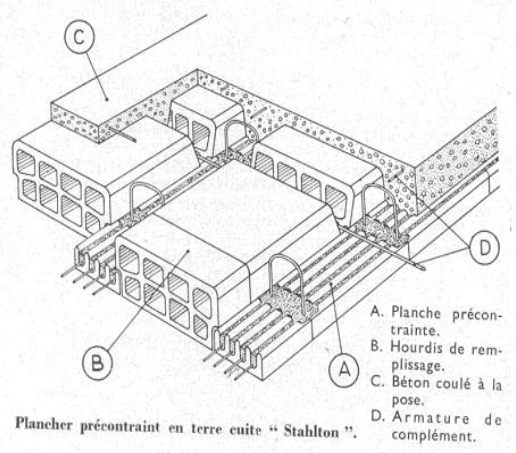

$$
\begin{aligned}
& \text { Key: } \\
& \text { A - Pre-stressed } \\
& \text { board. } \\
& \text { B - Hollow block } \\
& \text { of filling } \\
& \text { (case-bays). } \\
& \text { C - Concrete cast } \\
& \text { on site at the } \\
& \text { installation. } \\
& \text { D- The } \\
& \text { complement of } \\
& \text { reinforced } \\
& \text { frame. }
\end{aligned}
$$

Figure 13: Terracotta pre-stressed floor and a cast and vibration semiautomatic machine (Charrière [3]).

The STUP system produced floors that looked like prefabricated floors manufactured in the traditional way, however they were composed of beams holding a concrete rib cast in the ceramic hollow blocks. According to the profile of these hollow block floors, they were classified into three categories. Floors of STUP type, required concrete with a very high resistance which was very compact and easy to set up in relatively slim and narrow sections and was not influenced by the water absorption capacity of the hollow blocks. These floors were available for all the traditional uses. Their design permitted to the construction of elegant corbelled structures.

The Air Terminal of Nice-le-Var provides an example. The covered terrace of the freight building has four spans of $6.25 \mathrm{~m}$. This $32 \mathrm{~m}$ wide and $243 \mathrm{~m}$ long slab structure has an entire floor that was made at the Cagnes factory. Prestressed concrete beams are also incorporated in the external walls contributing great homogeneity to all the longitudinal supports (Charrière [3]).

The experience acquired in the factories showed the technical and economic advantages of pre-stressing in prefabrication. Not only did the pre-stressed mixed elements possess better technical qualities than the traditional floors, in particular because they resisted cracking, but they also opened new prospects to the terracotta industry. The long benches allowed a rational organization of the manufacturing sites because, pre-stressing permitted the manufacturing in line, which improved the specialization and skills of the teams and promoted a high degree of high efficiency. 


\section{Conclusions}

Many improvements were introduced to satisfy the high demand for housing and public buildings and also the consequence of the sociological and economic changes that took place in France after WWII. The floor is only one part of the structural ensemble, but the study of innovations in floor construction illustrates the progress and evolution of the construction industry in France during the reconstruction period post WWII.

The analysis of the construction details, materials used and execution clarify the evolution of the construction methods during the 1950s. The perfect association between concrete, ceramics and steel is traced in the floors of hollow blocks and in the first attempts to combine with concrete to manufacture the floors.

The introduction of prefabrication and pre-stressing gave an impulse to development of the construction techniques and also permitted fast execution in the building yard. Concrete and ceramics were combined perfectly: the concrete providing the framework and ceramics providing isothermal properties and structural strength for the floors and the prefabricated walls. There was a significant reduction in the dead load and thickness of the floors. The net savings on the prefabrication work depended on the method adopted and, of course, on the specific type and quality of the materials used. For example, at Courrège the mechanization and management of the construction process used permitted a single team of less than 30 men to compete entire work

It was not only the introduction of new material, designs and manufacturing processes, but the integrated management of production and construction that made such an important contribution to the development of the construction industry.

\section{References}

[1] Bradshow, R.E., Structural ceramics. Industrialized building and the structural engineer, Institution of structural Engineers, pp. 206-217, 1966

[2] Cazaneuve R. \& Peray E., Techniques et Architectures Revue, $15^{\mathrm{eme}}$ Série ${ }^{\circ}$ 2, pp. 76-80, September, 1955.

[3] Charrière M. J., Fabrication et utilisation des différents types d'éléments de construction en terre cuite et béton précontraints, fabriquées en France. Annales de l'Institut Technique du Bâtiment et des Travaux Publics, $\mathrm{n}^{\circ}$ 108, pp. 1177-1196, 1956

[4] Fayeton J., Techniques et Architectures Revue, $15^{\mathrm{eme}}$ Série no 2, pp.73-75 octobre 1955

[5] Vitale, F. J., Techniques et Architectures Revues $18^{\mathrm{eme}}$ Série n ${ }^{\mathrm{o}} 5$, octobre 1958.

[6] Kopp, A., Boucher, F. \& Pauly, D., L'architecture de la Reconstruction en France 1945 - 1953, Moniteur, Paris, 1982.

[7] _ The Quartering for the Republican Guard built on the ground at Courrège in Toulouse. Annales de l'Institut Technique du Bâtiment et des Travaux Publics, pp. 1205-1216, Décembre 1954. 